\title{
MACIZO/HUECO, SOLDADO/FUNDIDO, MORFOLOGÍA/TECNOLOGÍA. EL ÁMBITO TECNOLÓGICO CASTREÑO A TRAVÉS DE LOS TORQUES CON REMATES EN DOBLE ESCOCIA

\author{
SOLID/HOLLOW, SOLDERED/CAST, MORPHOLOGY/TECHNOLOGY. THE CASTRO \\ TECHNOLOGICAL DOMAIN SYSTEM THROUGH THE TORCS WITH DOUBLE \\ MOULDING ENDS
}

BARBARA ARMBRUSTER (*)

ALICIA PEREA $(* *)$

\section{RESUMEN}

Contraponemos la observación directa de las piezas y el estudio del proceso de fabricación, distribución y consumo, a la tradicional visión tipológica de los torques castreños. La variabilidad tecnológica es la característica que mejor define este material arqueológico, dentro del conjunto de la orfebrería del noroeste peninsular de la Edad del Hierro. Olvidamos su carácter de adorno y conceptualizamos el objeto como una inversión colectiva dentro de un espacio temporal que se inicia en el Bronce Final y se prolonga hasta más allá de la romanización.

\begin{abstract}
We oppose the direct observation of the artefacts and the study of the fabrication, distribution and consumption processes against the traditional typological view of the castro torcs. Technological variability defines best this particular archaeological material which forms part of the Iron Age goldwork in the northwest of the Iberian Peninsula. We
\end{abstract}

(*) Stiftung Schleswig-Holsteinische Landesmuseen Schloss Gottorf, Archäologisches Landesmuseum, Schloss Gottorf, D-24837 Schleswig.

(**) Dpto. de Prehistoria, Instituto de Historia, Centro de Humanidades. CSIC. Serrano 13. E-28001 Madrid. Correo electrónico: perea@ceh.csic.es.

El artículo fue remitido en su versión final el 12-I-2000.

(1) Estudio realizado dentro del Proyecto $A u A g$ que se viene financiando con los siguientes proyectos de investigación: DGICYT PB94-0129; DGICYT PB97-1132; CAM 06/0020/1997; CAM 06/0094/1998. Todos ellos bajo la dirección de Alicia Perea. forget its quality of adornment and conceptualize the $o b$ ject as a collective investment within a diachronic context beginning in the Final Bronze Age and extending into the Period of romanization.

Palabras clave: Torques. Edad del Hierro. Cultura Castreña. Oro. Sistemas.

Key words: Torcs. IronAge. Castro Culture. Gold. Systems.

\section{JUSTIFICACIÓN}

Creemos que un trabajo sobre orfebrería castreña requiere una justificación que, en nuestro caso, está en una nueva orientación metodológica enfocada al análisis tecnológico y reconstrucción del proceso de fabricación de un material que todavía se presenta como un desafío dentro del panorama de la arqueología peninsular del final de siglo.

El juego de palabras que preside el título no es una concesión efectista; sólo refleja el camino de una investigación que se inicia con el objeto, para llegar al sujeto. El carácter de estas oposiciones nos remite a la dicotomía de la semiótica de Eco (1995), a la oposición entre una semiótica de la significación y una semiótica de la comunicación; son preguntas que nos interrogan sobre la generación de un signo dentro de su propio sistema de comunicación; sobre los códigos semánticos que actuaron en el momento de la fabricación, uso y abandono de los 
torques castreños. Con génesis y código nos referimos a la oposición "regla versus proceso", es decir, a la posibilidad de llegar a conocer algunas de las reglas que rigieron el sistema de significados de una sociedad del pasado, cuyo proceso de comunicación se ha perdido para siempre, no es ya reconstruible. Dado que "en los procesos culturales, los dos fenómenos van estrechamente ligados" (Eco, 1995: 25), una explicación sobre los torques castreños va a ser siempre incompleta y en cierta medida equivocada.

Si comparamos los trabajos ya históricos, sin falta de remontarnos a Villaamil y Castro (1874), sino desde la época dorada de López Cuevillas (1932, 1951), Monteagudo (1952) y Bouza Brey (1965), con las publicaciones más recientes, como las de Pérez Outeiriño (1990) y Prieto Molina (1996), constatamos que la tipología con finalidad cronológica sigue siendo el método y la preocupación principal del investigador, aunque se adobe con distribuciones espaciales dentro del paisaje castreño, con pinceladas de identificación étnica, o argumentos sobre sistemas ponderales que ciertamente intentan abrir nuevas vías. En otros casos, también recientes, se renuncia a la explicación para hacer recopilación (Balseiro, 1994), trabajo ingrato pero necesario. Finalmente, hay quien logra trascender el marco morfológico para adoptar una perspectiva histórica, a la búsqueda de los orígenes y trayectorias del torques en las distintas épocas y sociedades que lo utilizaron (Castro Pérez, 1990, 1992).

En otros países, la orfebrería castreña suscita cierto interés. En Portugal, Ferreira da Silva (1986) recoge todo el material de ese país, con interesantes observaciones técnicas sobre algunos torques que considera, en términos generales, adornos masculinos. En Alemania tres autores integran los torques castreños en sus respectivos estudios sobre orfebrería de la Edad del Hierro; K. Raddatz (1969) recoge sesenta ejemplares peninsulares que considera un material homogéneo desde el punto de vista técnico y tardío desde el cronológico, dentro del siglo III al I a.C.; Lenerz de Wilde (1992) sigue fielmente los pasos de Raddatz; V. Pingel (1992) aumenta su recopilación a noventa ejemplares y acepta una cronología más antigua para algunos.

Dentro de este panorama, que no es necesario desarrollar porque otros lo han hecho ya (Pérez Outeiriño, 1982 y 1990; Prieto Molina, 1996; Balseiro, 1997), existen unas constantes, implícitas o explícitas, en la valoración de este material arqueológico: los torques son joyas o adornos personales, a la vez que objetos de prestigio; la ausencia de contextos es un límite insalvable para cualquier aproximación histórica y cronológica; la abundancia de oro en el territorio es explicación suficiente para la aparición de una orfebrería compleja, aún dentro de una sociedad campesina, tal y como actualmente se definen las agrupaciones sociales castreñas (Criado, 1992; Fernández-Posse y Sánchez-Palencia, 1998); existen concentraciones geográfico-tipológicas cuyo significado no es posible determinar.

Por oposición a este estado de cosas, hemos partido de una nueva conceptualización del torques, negando su carácter de adorno personal, negando la validez de la tipología como método para continuar su estudio, negando, finalmente, que la ausencia de contextos sea el chivo expiatorio de la situación. Como alternativa, proponemos los siguientes temas de análisis: a) la variabilidad tecno-morfológica es la característica que mejor lo define; b) el contexto del torques es precisamente la ausencia de contexto; c) el torques castreño es una inversión colectiva, no un adorno personal.

\section{LAS PIEZAS (2)}

El estudio que proponemos no pretende abarcar toda la población de los torques gallegos y portugueses, que se aproxima actualmente a los 120 ejemplares, sino una muestra de 24 -hay fragmentos, por lo que puede variar el número contabilizado, según el criterio- que seleccionamos tras establecer unas condiciones previas. Se trata de ejemplares que en todos los casos hemos podido estudiar con ayuda de medios ópticos o electrónicos, documentar con macrografía, medir y pesar directamente. Esto último lo consideramos de obligado cumplimiento dado que los datos que se manejan en la bibliografía actual están tomados de las publicaciones más antiguas, sobre todo de los trabajos de López Cuevillas, siendo en muchos casos

(2) Queremos agradecer muy sinceramente las facilidades y amabilidad de directores y conservadores que nos permitieron realizar este trabajo en los siguientes museos: Museo Arqueológico Nacional de Madrid, Museo Provincial de Lugo, Museo Provincial de Pontevedra, Museo Arqueológico e Histórico de La Coruña, Museo Nacional de Arqueología de Lisboa, Museo Nacional Soares dos Reis de Oporto y Museo Martins Sarmento de Guimarães. 
erróneos (3). Esto excluye, lógicamente, todos aquellos ejemplares conocidos únicamente por dibujos o referencias indirectas.

Desde el punto de vista morfológico constituye un grupo fácilmente diferenciable a simple vista, tanto con criterios intuitivos, como pretendidamente taxonómicos, en tipologías históricas y actuales. Los torques con remates en doble escocia han conformado generalmente un tipo independiente en la mayoría de las sistematizaciones (4), aunque quedan divididos en numerosos subtipos, variantes o escuelas que nosotros no vamos a tener en cuenta puesto que en la mayoría de los casos no están basadas en criterios que se hagan explícitos, sistemáticos o con capacidad de explicación. Así, para López Cuevillas (1951) este remate aparece tanto en la escuela asturiana como en la flaviense, esta última identificada en su momento por Cardozo (1942), siendo el criterio diferenciador la morfología y ornamentación de las varillas; igualmente, el grupo astur-norgalaico de Monteagudo (1952) se define por los terminales en doble escocia y coincide con la escuela asturiana de López Cuevillas, aunque también la varilla es rasgo diferenciador; más recientemente, Pérez Outeiriño (1990) establece para el norte de Portugal un prototipo teórico que llevaría remates en doble escocia y varilla de sección cuadrangular; finalmente, los terminales en doble escocia es un rasgo que se extiende a los tipos VI, VII y VIII de Prieto (1996), con una gran cantidad de subtipos en cada uno.

A la hora de elegir el material hemos prescindido, por tanto, de muchos de los rasgos que han servido tradicionalmente para agruparlo y clasificarlo, como la variabilidad dentro de los propios terminales, de las varillas, y de los tipos de ornamentación. En el lado opuesto, el de los torques no escogidos, están todos los ejemplares con remates piriformes y en campánula. Desde este punto de vista, nuestro catálogo incluye más del $80 \%$ de la población total de los torques con remates en doble escocia.

La descripción que damos a continuación es estrictamente tecnológica, fruto del examen minucioso de las huellas de trabajado de todos los ejemplares.

(3) Llamamos la atención sobre este hecho, dado que algunos estudios sobre sistemas metrológicos se basan en datos antiguos, no contrastados posteriormente.

(4) Estamos de acuerdo con Ladra Fernández (1997-98) en lo escasamente afortunado de la denominación "doble escocia" que constituye además un cajón de sastre, pero no hemos encontrado una alternativa mejor, quizá por falta de imaginación o empeño.
Catálogo (con medidas en cm, siempre máximas si nada se indica, y pesos en gr):

ASTORGA, León, Museo Arqueológico Nacional ( $\mathrm{N}^{\circ}$ Inv.16.854). Diámetro torques: 16,5 , grosor: 1.2; altura terminales: 3.2, diámetro máx.: 2.4, diámetro mín.: 1.8; Peso: 500. Aro y terminales macizos. Sin ornamentación.

- Contexto: sin datos.

BURELA, Chao do Castro, Lugo, Museo Provincial de Lugo (Balseiro ${ }^{\circ}$ 24). Diámetro torques: 21.5, grosor aro: 1.9; terminales altura: 6.9, diámetro máx.: 6.5, diámetro mín.: 2.1; peso: 1806.7.Aro macizo, terminales huecos. Alambre enrollado en los extremos del aro y cenefas de cordón suelto en el centro.

- Contexto: en un castro, durante labores agrícolas.

CANGAS DE ONIS, Asturias, MuseoArqueológico Nacional.

Torques A ( $\mathrm{N}^{\mathrm{o}}$ Inv. 33.132), diámetro torques: 17.5, grosor aro: 1.0; terminal altura: 3.9, diámetro máx.: 3.2, diámetro mín.: 2.5 ; peso: 203. Aro y terminales huecos. Ornamentación de estrías longitudinales en el aro. Disco exterior del terminal con motivo de triángulos rellenos de puntos y esfera central. Con sonajero.

Fragmento de aro $\mathrm{B}\left(\mathrm{N}^{\circ} \mathrm{Inv} .33 .134\right)$, grosor aro: 0.9; peso: 140.7. Macizo. Ornamentación de placas circulares de hilo en espiral con esfera central.

Fragmento de aro $\mathrm{C}\left(\mathrm{N}^{\circ}\right.$ Inv. 33.135), grosor aro: 0.7; peso: 33.8. Macizo.

Fragmento de aro $\mathrm{D}\left(\mathrm{N}^{\circ}\right.$ Inv. 33.133): grosor aro: 1.4; peso: 145. Macizo. Alambre enrollado, placas circulares de hilo en espiral con esfera central, y motivos a punzón.

Terminal E ( $\mathrm{N}^{\mathrm{o}}$ Inv. 33.136) altura: 4.2, diámetro máx.: 3.2, diámetro mín.: 2.6; peso: 35. Hueco. Ornamentación del disco exterior con motivo de corchetes realizadas con punzón complejo.

Terminal $\mathrm{F}\left(\mathrm{N}^{\circ}\right.$ Inv. 33.137) altura: 4.8, diámetro máx.: 3.5, diámetro mín.: 2.8; peso: 73.3. Hueco. Disco exterior con motivo de postas y esfera central, y disco interior con motivo cordelado.

Terminal G ( $\mathrm{N}^{\circ}$ Inv. 33.138) altura: 4.8, diámetro máx.: 3.6, diámetro mín.: 2.9; peso: 57. Hueco. Disco exterior con motivo de postas y esfera central, y disco interior con motivo cordelado.

- Contexto: colección Soto Cortés, procedencia insegura. 
ESTELA, Póvoa de Varzim, Museo Nacional Soares dos Reis (CMP 145), Oporto. Terminal altura: 2.8, diámetro máx.: 2.2, diámetro mín.: 1.6; peso: 28. Macizo. Disco exterior con trisquel realizado con punzón complejo.

- Contexto: hallazgo de 1908 dentro de una vasija, junto con un collar articulado, dos arracadas y 16 tortas de oro y plata.

FOXADOS, STA. MARÍA DE, Curtis, Betanzos, La Coruña, Museo Provincial de Pontevedra. Diámetro torques: 14 ; altura terminales: 4.0 , diámetro máx.: 4.7, diámetro mín.: 2.6; peso: 593. Aro macizo y terminales huecos. Sistema de unión entre aro y terminales por machihembrado. Discos exteriores de los terminales con filigrana al aire entrelazada y esfera central.

- Contexto: en el lugar del Castrelo, antiguo castro, en 1932, dentro de una vasija junto con 35 tortas de aleación de oro y plata, un brazalete de oro, fragmentos de varillas de torques, y cuatro torques más de extremos en perilla.

LEBUÇÀO, Valpaços, Vila Real, Museo Martins Sarmento, Guimarães. Diámetro torques: 14.7, grosor aro: 1.1; altura terminales: 3.4, diámetro máx.: 3.1, diámetro mín.: 2.4; peso: 199 gr. Aro macizo, terminales huecos. Disco exterior de los terminales con roseta y cordelado de punzones simples y complejos.

- Contexto: a fines del siglo pasado, en trabajos agrícolas, junto con un brazalete, otro torques fragmentado y dos remates campanulares.

LUGO, Museo Arqueológico Nacional ( $\mathrm{N}^{\circ}$ Inv. 16.856). Diámetro torques: 13.2 , grosor aro: 0.9 ; terminales altura: 2.5, diámetro máx.: 2.3, diámetro mín.: 1.9; peso: 137. Aro macizo, terminales huecos. Sin ornamentación. Con sonajero.

- Contexto: sin datos. Ingresado en 1891.

MADORRA, LA, Cospeito, Lugo, Museo Arqueológico Nacional.

Torques 1 ( $\mathrm{N}^{\circ}$ Inv.72/64/1), diámetro torques: 11.8 , grosor aro: 0.9 ; terminales altura: $1.3 / 1.5$, diámetro máx.: 1.5, diámetro mín.: 0.9; peso: 184.

Torques 2 ( $\mathrm{N}^{\circ}$ Inv.72/64/2), diámetro torques: 15 , grosor aro: 0.9 ; terminales altura: 2.2 , diámetro máx.: 2,0, diámetro mín.: 0.8; peso: 218.

Torques $3\left(\mathrm{~N}^{\mathrm{o}}\right.$ Inv.72/64/3), diámetro torques: 13 , grosor aro: 0.7 ; terminales altura: 2.0 , diámetro máx.: 1.7, diámetro mín.: 0.8; peso: 175.
Los tres con aro y terminales macizos; alambre enrollado en los extremos del aro y cenefas de cordón suelto en el centro.

Torques 4 (NoInv. 72/64/4), diámetro torques: 12 , grosor aro: 0.5 ; terminales altura: 1.4 , diámetro máx.: 1.6, diámetro mín.: 0.9; peso: 155 . Aro y terminales macizos. Ornamentación de punzón simple circular en el aro.

- Contexto: mercado de antigüedades, procedencia dudosa.

MARZÁN, Cú do Castro, Punta de Marzán, Foz, Lugo. Museo Provincial de Lugo ( $\mathrm{N}^{\circ}$ Inv.1974/2/ $15)$. Torques diámetro: 16 , grosor aro: 1.4 ; terminales altura : 4.2, diámetro máx.: 3.7, diámetro mín.: 1.5; peso: 523.3. Aro macizo y terminal hueco (falta uno de los terminales). Alambre enrollado en los extremos del aro y cenefas de cordón suelto en el centro.

- Contexto: en un castro.

MELIDE, La Coruña, Museo Prov. de Lugo ( ${ }^{\circ}$ Inv. 1974/2/17). Torques diámetro: 20, grosor aro: 1.3; terminales altura: 3.4 , diámetro máx.: 3.2, diámetro mín.: 1.5 ; peso: 399 . Aro macizo y terminales huecos. Sin ornamentación. Con cascabel.

- Contexto: hallazgo de 1876 a $6 \mathrm{~km}$. de la villa de Melide.

PARADELA DO RIO, Montalegre, Vila Real, Museo Nacional de Arqueología de Lisboa.

Torques A ( $\mathrm{N}^{\circ}$ Inv.: 566), diámetro torques: 15 , grosor aro: 1.0; terminales altura: 3.0, diámetro máx.: 2.9, diámetro mín.: 1.6; peso: 183. Aro macizo y terminales huecos. Ornamentación de rosetas realizadas con punzón complejo en el centro del aro y disco exterior de los terminales en donde se añade esfera central.

Torques B ( $\mathrm{N}^{\circ}$ Inv.: 568), diámetro torques: 13.6, grosor aro: 0.7 ; terminales altura: 2.8 , diámetro máx.: 2.2, diámetro mín.: 1.6; peso: 93.7. Aro macizo y terminales huecos. Sin ornamentación excepto por una esfera en el centro del disco exterior de los terminales.

- Contexto: hallazgo de 1958 junto con un torques de extremos piriformes.

PROVINCIA DE LUGO (TORQUES DE LOS PATOS), Museo Prov. de Lugo (Balseiro n ${ }^{\circ} 6,7$ y 8 ). Fragmentado. Grosor aro: 0.7; terminales altura: 3.3/2.9, diámetro máx.: 2.8/2.4, diámetro mín.: 2.0/ 1.4; peso total calculado: 225 . Aro macizo y termi- 
nales huecos. Ornamentación con punzón simple de aves en el aro y roseta en el disco exterior de los terminales realizada con punzón complejo.

- Contexto: hallazgo de 1859 en un castro.

RECADIEIRA I, Mondoñedo, Lugo, Museo Prov. de Lugo ( ${ }^{o}$ Inv.: 1974/2/16). Torques diámetro: 16.6, grosor aro: 0.7 ; terminales altura: 2.3 , diámetro máx.: 1.9, diámetro mín.: 1.0; peso: 238.2.Aro y terminales macizos. Sin ornamentación.

- Contexto: encontrado hacia 1885 en el castro del mismo nombre. De este mismo castro proceden diferentes hallazgos, en 1840 y en 1984, de tortas o lingotes planoconvexos.

RECADIEIRA II, Mondoñedo, Lugo, Museo Prov. de Lugo ( ${ }^{\circ}$ Inv.: 1974/2/14). Torques diámetro: 22 , grosor aro: 1.25 ; terminales altura: 3.5 , diámetro máx.: 3.8, diámetro mín.: 1.3; peso: 1.183. Aro y terminales macizos. Alambre enrollado en los extremos del aro; impresiones irregulares de punzón simple en la zona de unión al aro de los terminales.

- Contexto: encontrado en 1889 en un castro, por la misma persona que el ejemplar anterior pero en distinta fecha. De este mismo castro proceden diferentes hallazgos, en 1840 y en 1984, de tortas o lingotes planoconvexos.

RIBADEO, Museo Arqueológico Nacional $\left(\mathrm{N}^{\circ}\right.$ Inv.: 1943/9). Torques diámetro: 15.7, grosor aro: 1.1; terminales altura: 2.8, diámetro máx.: 2.75 , diámetro mín.: 1.2; peso: 287.7. Aro macizo y terminales huecos. Sin ornamentación.

- Contexto: sin datos.

SAN LORENZO DE PASTOR II, O Pino, La Coruña. Museo Arqueológico de La Coruña (MAC 120). Torques diámetro: 22 , grosor aro: 1.2 ; terminales altura: 3.1, diámetro máx. 2.7, diámetro mín.: 1.1; peso: 445.3. Aro macizo y terminales huecos. Alambre enrollado en los extremos del aro, y placas circulares de hilo en espiral; circulos concéntricos en el disco exterior de los terminales.

- Contexto: en un castro, junto con dos torques más, uno con extremos piriformes y otro en doble escocia.

SIN PROCEDENCIA, Museo Provincial de Lugo ( $N^{\circ}$ Inv.: 1974/2/42). Torques diámetro: 15, grosor aro: 0.9 ; terminales altura: 2.6, diámetro máx.: 2.4, diámetro mín.: 1.3; peso: 159.4. Aro macizo y terminales huecos. Sin ornamentación.

- Contexto: colección Gil Varela, sin datos.

VILAS BOAS, Vila Flor, Bragança, Museo Arqu. Nacional de Lisboa ( $\mathrm{N}^{\circ}$ Inv.: 567). Torques diámetro: 20 , grosor aro: 1.8 ; terminales altura: 5.1 , diámetro máx.: 5.4/5.6, diámetro mín.: 4.1/4.5 ; peso: 387.3. Aro tripartito y terminales huecos. Ornamentación de aro y terminales con filigrana, filigrana al aire, granulado, estampado y elementos plásticos añadidos, en forma de ave. Con sonajero.

- Contexto: encontrado en 1965 cerca de un castro.

VIVEIRO, Lugo, Museo Provincial de Lugo (NoInv.:1974/2/18). Fragmentado. Grosor aro: 0.8; terminal altura: 2.5 , diámetro máx.: 2.25 , diámetro mín.: 1.2; peso: 136.7. Aro y terminales macizos. Ornamentación con punzón simple en el aro.

- Contexto: procedencia dudosa de un hallazgo de 1883 en un castro.

\section{LAS TÉCNICAS}

No hemos considerado necesario hacer una descripción técnica en detalle para cada pieza porque alargaría en exceso este texto, daremos una descripción genérica, haciendo alusión a cada pieza en particular cuando sea pertinente.

\section{El trabajo de preparación}

La característica principal y común de estos torques es su división mínima en tres partes, un aro y dos terminales, macizos o huecos, unidos entre sí mediante soldadura o vaciado adicional; hay ejemplares complejos que pueden estar compuestos por más de tres elementos, en función del aro, como el de Vilas Boas, o en función de los terminales.

Los terminales pueden ser macizos y estar fabricados en una sóla pieza, vaciada a la cera perdida sobre un pequeño núcleo y posteriormente soldados al aro, como los ejemplares de La Madorra y Estela, o bien ser huecos y estar compuestos de tres o más elementos de chapa o lámina gruesa (Lám. I): uno o dos cuerpos centrales, con eje de simetría, y dos discos de cierre, interior y exterior, todo ello soldado entre sí y al aro. Pero también se da el caso de haber fabricado y unido los terminales en una sóla operación de vaciado adicional a la cera perdi- 


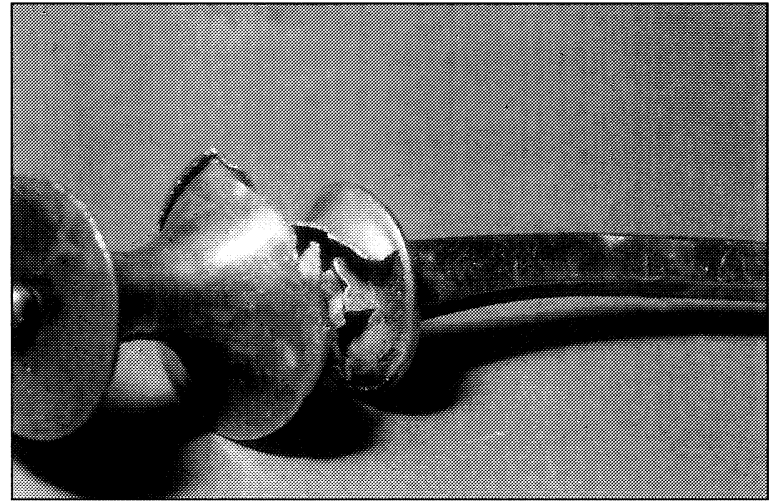

Lám. I. Terminal fragmentado del torques B de Pradela do Rio, donde se pueden ver las soldaduras de los distintos elementos del remate hueco y la fijación del aro, que encaja en el disco interior, sobrepasándolo. El grosor de la chapa oscila entre $0,3-0,4 \mathrm{~mm}$.

da sobre el propio aro, como en Astorga o Recadieira II (Lám. II). Cada una de estas partes se planifica y fabrica con independencia, teniendo en cuenta el producto final. La decoración es otra fase importante porque requiere disponer de un patrón previo y unas herramientas específicas: compás para trazar círculos y composiciones de rosetas, postas o trisqueles; punzones simples o complejos; varillas, hilos, alambres, gránulos de remate, elementos plásticos, etc.

En cuanto a la materia prima, el orfebre castreño se limita al trabajo del oro, con empleo de la plata como producto secundario para núcleos y rellenos, pero el color o el contraste de matices está prácticamente ausente de este tipo de orfebrería. Las formas huecas se asocian a la idea de ahorro de metal, más que a otras consideraciones de carácter

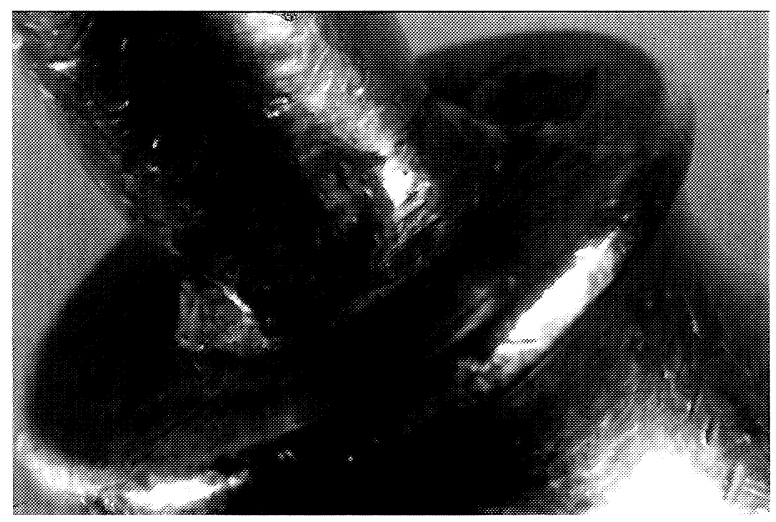

Lám. II. Remate del torques de Astorga fabricado y unido al aro en la misma operación de vaciado adicional. Detalle de la zona de unión. estructural. Un torques macizo, aún de pequeñas dimensiones, consume una cantidad de oro importante, de manera que las formas huecas o rellenas suponen un ahorro considerable de materia prima.

Otro elemento significativo es el sonido. Algunos de estos ejemplares han conservado en el interior de uno de los terminales huecos un fragmento de metal o piedrecita que suena al moverse, por ejemplo en los torques de Cangas de Onís, Lugo, Melide, Ribadeo y otros más que aquí no consideramos; en el caso del torques de Vilas Boas el sonajero se sitúa en la zona del aro.

\section{Técnicas de fundición}

Se parte siempre de un lingote fundido en barra para la fabricación de los aros macizos, varillas, alambres o hilos gruesos, chapas o láminas, con ayuda de un crisol para fundir el oro y un moldelingotera, abierto o cerrado.

La cera perdida permite la fabricación de formas complejas (Hunt, 1980). Se comienza modelando en cera el objeto, y añadiendo canales de llenado en el mismo material. Este modelo se cubre de sucesivas capas de arcilla muy depurada que van formando el molde de fundición. Una vez seco y habiendo derretido la cera mediante calentamiento, se rellena el hueco dejado por ésta con el oro fundido. Es necesario romper el molde para extraer la pieza vaciada; posteriormente se cortan los canales de llenado y se pule la superficie. Mediante esta técnica se fabricaron los discos de remate de los terminales F y G de Cangas de Onís que presentan distintas decoraciones imitando filigrana y granulado en forma de cordelado y postas (Láms. III, IV). Igualmente, todos aquellos ejemplares con remates macizos que presentan un pequeño hueco para la fijación del aro.

La fusión o fundición adicional (Drescher, 1958) es una variante de la cera perdida que se utiliza para la unión de dos elementos, en el caso de los torques para unir los terminales macizos al aro (Lám. II); es una combinación tecnológica de fabricación y de unión, aunque también es muy frecuente su uso como técnica de reparación.

Estas dos técnicas están documentadas en la orfebrería peninsular desde la Edad del Bronce, por ejemplo, en las tazas del depósito de Caldas de Reyes, Pontevedra (Armbruster, 1996). Dos ejemplos del Bronce Final que habría que destacar, porque unen las dos variantes de cera perdida, son el

T. P., 57, n. $^{\circ} 1,2000$ 


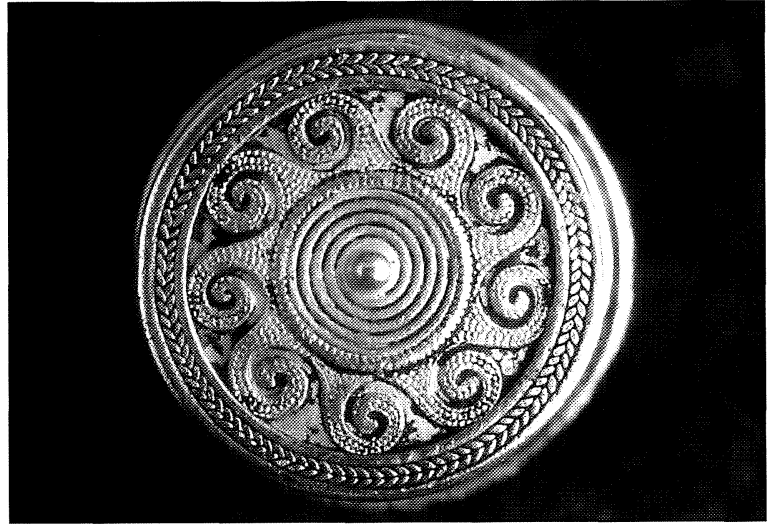

Lám. III. Disco exterior del terminal F de Cangas de Onís con ornamentación de postas y espiral central imitando filigrana y granulado.

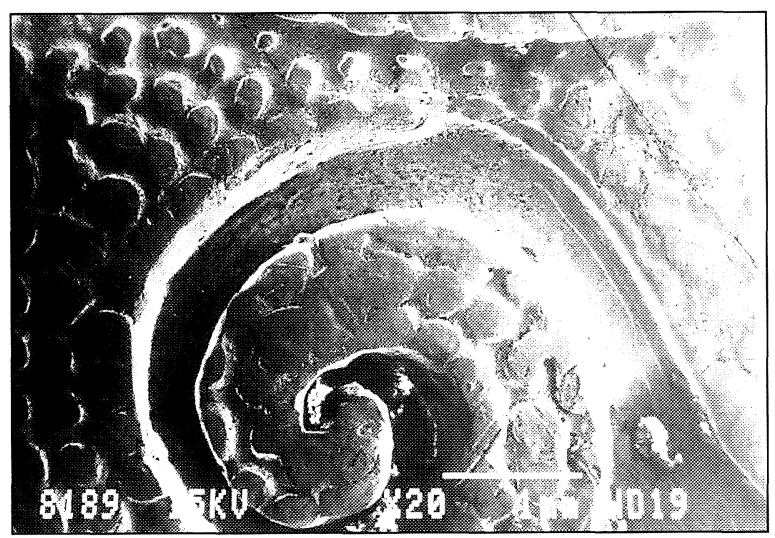

Lám. IV. Micrografía mostrando las características del terminal $\mathrm{F}$ de Cangas de Onís, fundido a la cera perdida (Micrografía realizada en el microscopio electrónico del CENIM).

torques de Sintra, Lisboa (Armbruster, 1995) y el brazalete de Cantonha, Braga (Armbruster y Perea, 1994: 75).

\section{La deformación plástica, aros e hilos}

La fabricación de aros macizos, alambres, hilos gruesos, chapas y láminas, se basa en técnicas de deformación plástica (forjado, martillado), cuyo fundamento se apoya en las propiedades mecánicas del metal -maleabilidad y ductilidad. Partiendo del lingote fundido, se fabrican mediante martillado sobre el yunque todos estos elementos estructurales u ornamentales.

No tenemos indicios del empleo de la hilera para la fabricación de hilos; todos los hilos finos emplea-

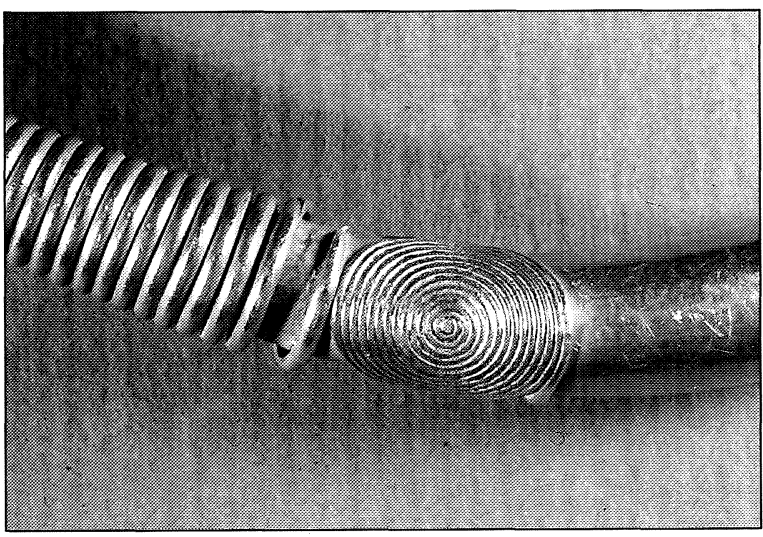

Lám.V. Aro del torques de San Lorenzo de Pastor II con alambre de sección plano-convexa enrollado y placa de hilo en espiral.

dos en la ornamentación de filigrana están fabricados mediante la antigua técnica mediterránea de la torsión de una fina tira laminar (Formigli, 1993: fig. 2-5), cuya prueba es la huella helicoidal que recorre longitudinalmente la superficie de estos hilos y que puede estar más o menos enmascarada por el desgaste de uso.

Los elementos trabajados por deformación plástica que se han documentado en los torques son los siguientes (Láms. V, VI, VII):

- Aros: en forma de barra de sección cuadrangular o romboidal, y circular; frecuentemente se combinan en el mismo aro una sección circular central y dos secciones poligonales en los extremos.

- Hilos/alambres: de sección circular, cuadrangular y planoconvexa.

- Hilos: de sección cuadrangular torsionados.

- Hilos gruesos combinados: de sección circular formando un cordón abierto.

\section{El trabajo sobre lámina, cuerpos huecos}

La fabricación de chapas y láminas a partir de un lingote se consigue mediante martillado sobre yunque. Esta fuerte deformación plástica (Nicolini, 1990: lám. 217) requiere sucesivos y frecuentes recocidos en el horno que devuelvan al metal su maleabilidad, en un trabajo que consume mucho tiempo y energía, sin embargo, el trabajo de martillado se realiza siempre en frío.

Esta técnica se utiliza para fabricar formas huecas y voluminosas con un mínimo gasto de materia prima. Los terminales huecos de los torques están fabricados generalmente en chapa a partir de cuatro 


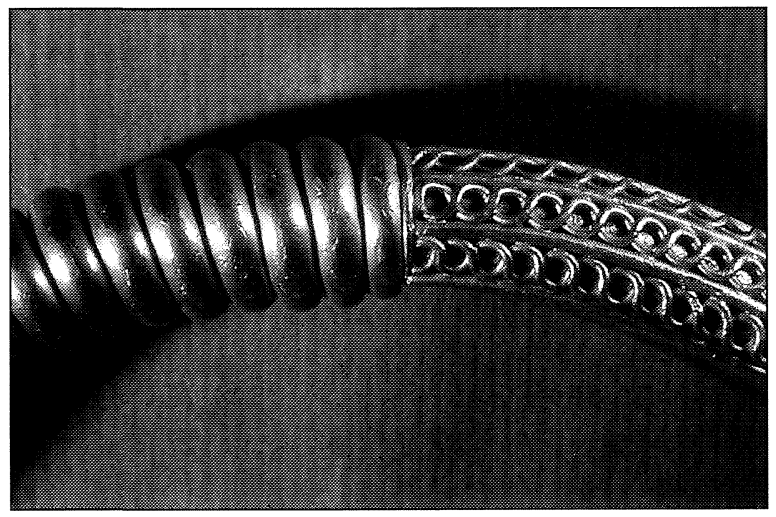

Lám. VI. Aro del torques de Burela con grueso alambre de sección plano-convexa enrollado y cenefa de cordelado con hilos de sección circular, fabricados por deformación plástica.

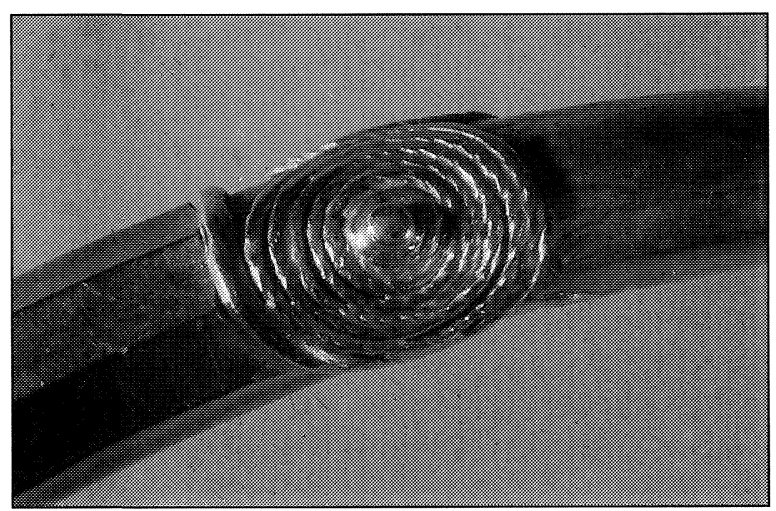

Lám. VII. Fragmento del aro B de Cangas de Onís que combina la sección circular con la poligonal. Ornamentación de placa circular de hilo torsionado en espiral y esfera central.

elementos independientes: dos en forma de escocia o cilindro de paredes cóncavas, y dos discos, uno que cierra el terminal por su extremo y otro que sirve como base de unión con el aro (Lám. I); pocas veces encontramos el cuerpo central con eje de simetría fabricado en una sóla pieza. En torques de calidad y bien acabados es difícil identificar las soldaduras que unen todos estos elementos entre sí, pero en otros, por ejemplo en Cangas de Onís, las soldaduras han fallado, quedando los elementos separados. Por otro lado, observamos frecuentemente una pequeña perforación en cada terminal, realizada con un punzón de punta cónica o piramidal, en el disco de unión al aro o en un lateral, para permitir la evacuación de aire y gases que se producen en el interior del cuerpo hueco durante el proce-

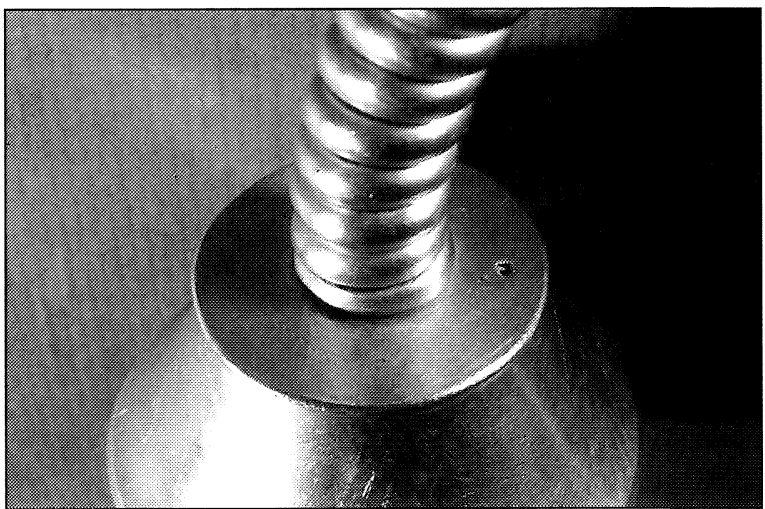

Lám. VIII. Perforación, para evacuación de gases, en el disco interior del terminal del torques de Burela.

so de soldadura y que podrían arruinar la operación de no contar con un sistema de salida (Lám. VIII).

Este tipo de trabajo sobre lámina o chapa se documenta en el Bronce Final, con independencia de su característica más peculiar que es el objeto macizo. A la vista de algunos trabajos sobre lámina, como los revestimientos y apliques -probablemente de armas- del depósito de Villena, Alicante (Armbruster, 1999), podemos decir que el origen de esta técnica en la cultura castreña puede relacionarse con la tradición del Bronce Atlántico. En el repertorio tecnológico de Villena no se documenta la soldadura por lo que todos esos elementos ornamentales, como cilindros de paredes cóncavas y semiesferas (Armbruster, e.p.: láms. 111, 112), son objetos abiertos, nunca cerrados como en el caso de los terminales castreños. Pero también existen otros ejemplos de cuerpos tridimensionales huecos en el Bronce Final atlántico como los aros de los torques del conjunto deAlamo, Beja (Inventario, 1993: 74-83).

\section{Elementos ornamentales}

Una vez terminada la estructura del torques, el orfebre tiene que planificar la distribución de la ornamentación, la cantidad de materia prima para los elementos complementarios, el patrón decorativo y las herramientas necesarias. Prueba de esta planificación son las huellas dejadas por el compás en un diseño inacabado de un torques de la región de Chaves (5) (Lám. IX).

Existe una gran variabilidad de elementos deco-

(5) Este nuevo hallazgo todavía inédito, compuesto por dos torques de extremos en doble escocia y un terminal en campánula, es interesante no sólo porque documenta el punto de apoyo del 
rativos en los torques estudiados que podemos enumerar sucintamente:

- Improntas de punzones, simples o complejos, sobre metal macizo (terminal torques de Recadieira II y aro del torques de Viveiro) o sobre lámina de un cuerpo hueco (San Lorenzo de Pastor II, Lebuçâo, Paradela do Rio, Provincia de Lugo, Vilas Boas) (Láms. IX, X).

- Varillas de sección plano-convexa, circular u ovalada, enrolladas cubriendo los dos tercios de los extremos del aro (Burela, Recadieira II, Marzán, San Lorenzo de Pasto II, La Madorra 1, 2 y 3) (Láms. V, VI).

- Hilos gruesos de sección circular, lisos, fabricados por martillado, formando un patrón decorativo de cordón, cordón suelto o cordelado (Burela, La Madorra 1, 2 y 3, Marzán) (Lám. XII); hilos finos fabricados por torsión de una cinta laminar (Foxados, Vilas Boas) (Lám. XI); hilos de sección cuadrangular torsionados (Marzán) (Lám. XII).

- Gránulos aislados, relativamente grandes, en el centro de los discos de los terminales (Cangas de Onís, Lebuçâo, Paradela de Rio); esferas de granulado (Vilas Boas) (Lám. XIII).

- Elementos plásticos añadidos, laminares, en forma de ave (Vilas Boas) (Lám. XIII).

- Discos ornamentales de los terminales fabricados a la cera perdida imitando filigrana y granulado (Cangas de Onís) (Láms. III, IV).

- Placas circulares de espirales de hilo de sección circular, bien fundidas a la cera perdida o bien fabricadas a partir de hilos de filigrana soldados entre sí (Cangas de Onís, San Lorenzo de Pastor II) (Láms.V, VII); este tipo de ornamentación es característico y mucho más frecuente en los torques de remates piriformes.

Todos estos elementos ornamentales, lo mismo que los terminales, están fijados, total o parcialmente, mediante soldadura metálica, esto es, mediante empleo de una aleación con menor punto de fusión que los elementos a unir, tal y como se documenta en toda la orfebrería prerromana de la Península, salvo excepciones muy contadas (Perea, 1990);

compás, empleado en el diseño del círculo de seis postas en el disco exterior de un remate y trazado posteriormente con punzón complejo, sino porque documenta igualmente la preparación de la soldadura entre el extremo y el aro con el orificio de expansión situado esta vez en el aro y no en el terminal. También se puede observar la soldadura rota entre las chapas que forman la doble escocia, soldadura que permanece inapreciable en otras zonas en que no ha fallado. Agradecemos al Dr. Luis Raposo, director del Museu Nacional de Arqueologia de Lisboa donde se encuentran depositadas las piezas, el permiso para examinar las piezas que serán publicadas en detalle por el profesor A.C. Ferreira da Silva.

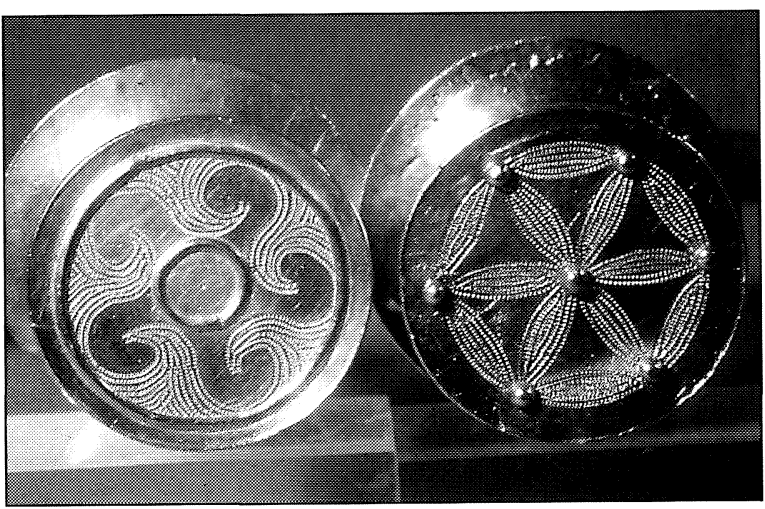

Lám. IX. Huella de compás para la realización de la ornamentación con punzón complejo en dos terminales de sendos torques procedentes de Chaves, Portugal (inéditos).

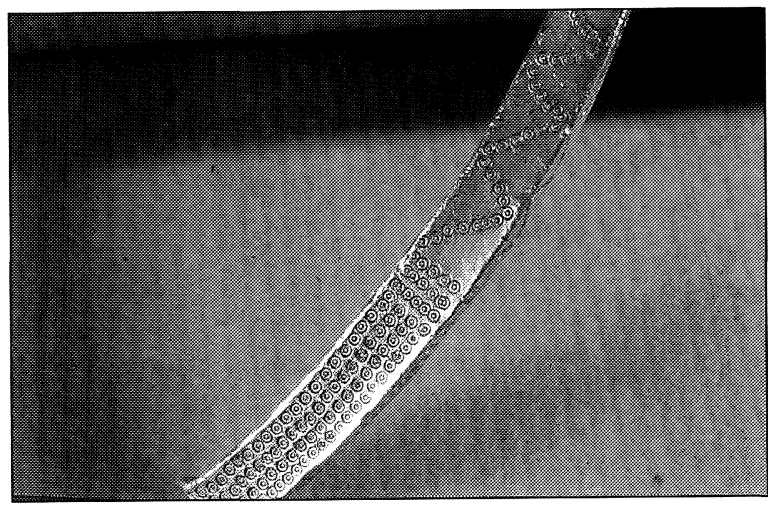

Lám. X. Ornamentación con punzón simple en el aro del torques de Viveiro.

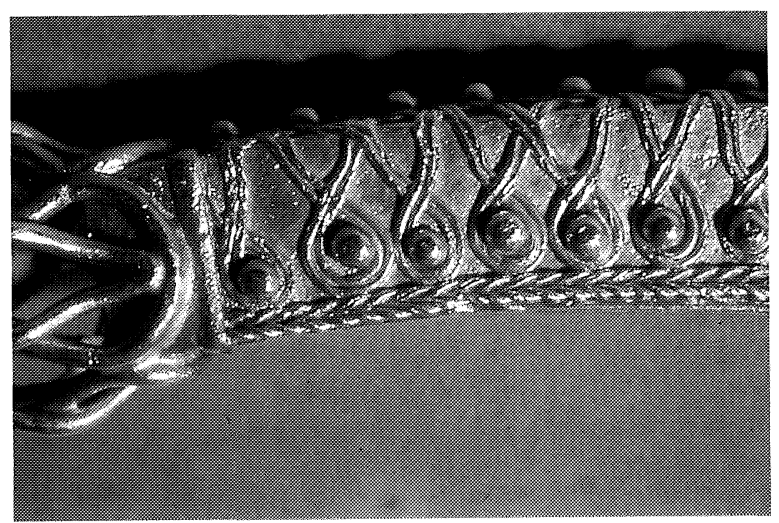

Lám. XI. Filigrana sobre el aro del torques deVilas Boas, realizada con hilos finos que presentan huella helicoidal sobre su superficie.

prueba de ello son los restos de material soldante, en forma de pequeñas laminitas, que se han observado tanto en la unión de los terminales al aro, como de los hilos y placas decorativas. 


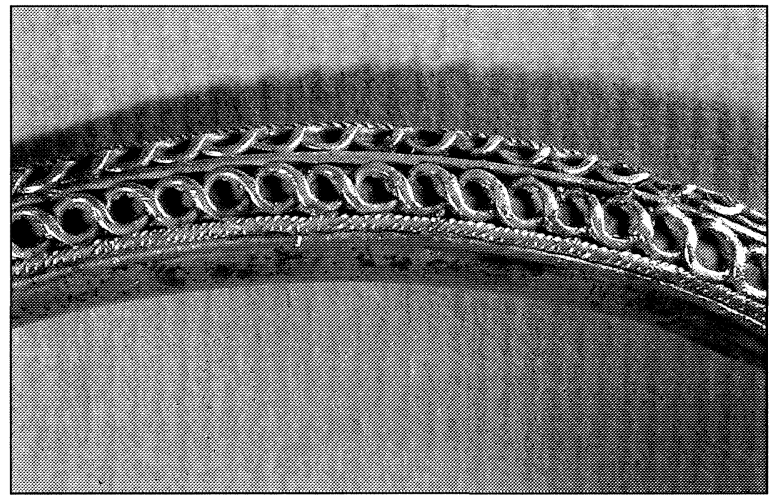

Lám. XII. Hilos de sección cuadrangular, torsionados sobre sí mismos, enmarcando una cenefa de cordón suelto en el torques de Marzán.

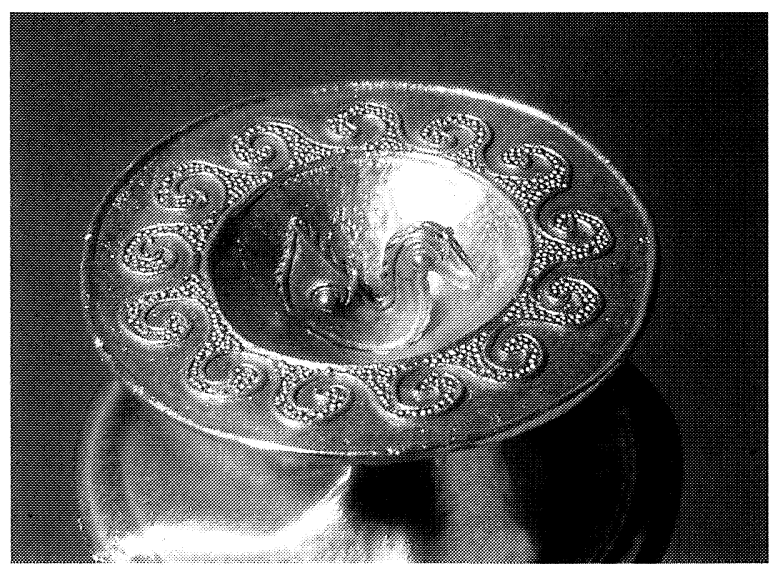

Lám. XIII. Ornamentación de los terminales del torques de Vilas Boas con un elemento plástico añadido en forma de ave y granulado rellenando un motivo de postas.

\section{Ornamentación con punzones simples y complejos}

El origen de la ornamentación de superficies metálicas con punzones y cinceles se remonta a la tradición del Bronce Final Atlántico; en forma de líneas incisas trazadas con cincel, como en los torques del ámbito tecnológico Sagrajas/Berzocana (Perea, 1995); en forma de puntillado en hueco sobre metal macizo, marcado mediante punzón apuntado, como en los torques de Baiôes, Viseu (Inventario, 1993: 64-67) y Azuaga, Badajoz (Armbruster, e.p.: lám. 14, 5-7); o bien con punzones decorativos de círculos concéntricos, como en el depósito deAlamo, Beja (Inventario, 1993: 74-83). En esta misma época aparece ya una nueva herramienta: el punzón complejo, que permite una orna- mentación continua a base de elementos repetitivos idénticos, por ejemplo sobre los cuencos de Axtroki, Guipúzcoa (Armbruster, e.p.: láms. 13-14), aunque sólo en su variante de línea recta. Esta misma técnica decorativa se documenta en toda Europa, incluso en el Bronce Nórdico. Conocemos algunos hallazgos de punzones complejos asociados a punzones simples de círculos concéntricos en depósitos del Bronce Final francés, por ejemplo, en el de Larnaud, Jura (Nicolardot y Gaucher, 1975: 36, fig. 2-3) y en el depósito de fundidor de Génélard, Saône-et-Loire (Thevenot, 1998: fig. 5-6).

A este tipo de herramienta, capaz de generar un motivo ornamental repetido, lo hemos llamado punzón complejo. Hasta la fecha nadie lo había identificado ni descrito, por lo que nos parece justificada una descripción en detalle.

El punzón complejo tiene forma y función semejante al filete de encuadernador, herramienta de impresión de libros de lujo, metálica, con forma de punzón de extremo ancho y curvado donde se sitúa el motivo decorativo en resalte, que aplicado sobre papel o cuero, deja una impronta lineal de elementos repetidos (Armbruster, 1998: 56, fig. 7). Se maneja mediante golpes de martillo, comenzando por el primer motivo del extremo curvo y terminando por el último, en un movimiento de balanceo; se sigue repitiendo el proceso, colocando nuevamente el extremo de la herramienta en el último motivo estampado hasta completar la serie; de este modo se consigue una línea, que trazada por orfebres expertos es absolutamente homogénea, sin saltos ni superposiciones (Fig. 1). La forma curva de la he-

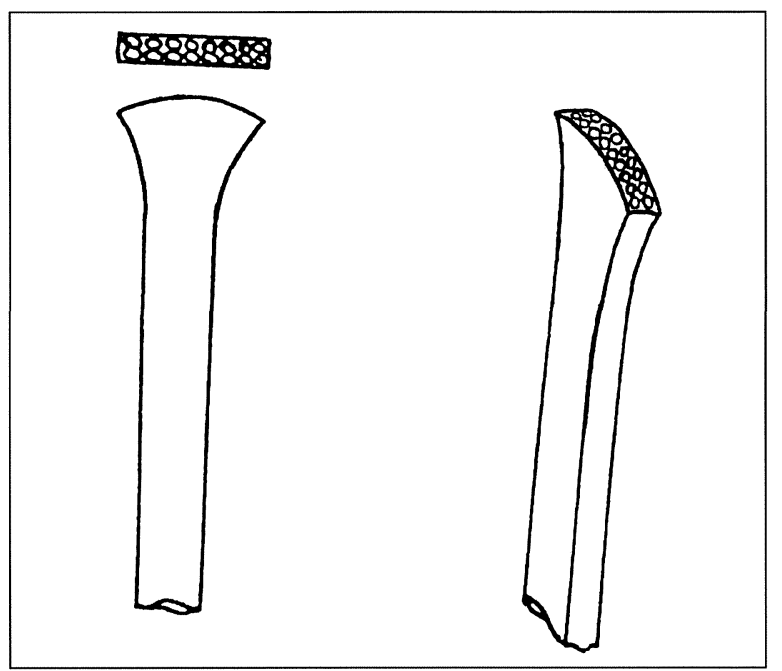

Fig. 1. Reconstrucción de un punzón complejo con extremo ancho y curvado. 


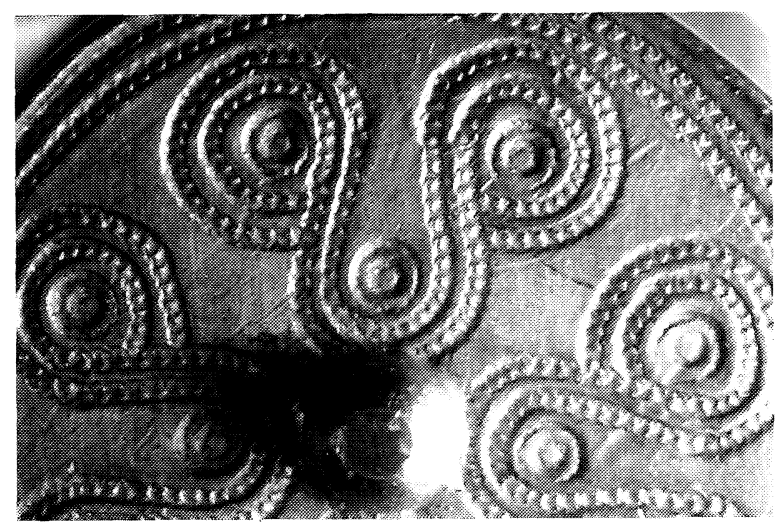

Lám. XIV. Disco exterior del terminal E de Cangas de Onís ornamentado con un motivo de corchetes realizados con punzón complejo.

rramienta facilita la estampación continuada y la realización de líneas decorativas curvas, en círculo o en espiral y el relleno de espacios en reserva (Láms IX, XIV).

En la orfebrería castreña hemos documentado la versión más compleja de esta herramienta, con improntas de una o dos filas paralelas de círculos, círculos con punto central, y muescas en forma de escalera. Gracias a los fallos de manejo se puede averiguar la longitud del extremo de la herramienta y el número de motivos que pueden estamparse a la vez. El ejemplo más elaborado sobre una pieza de orfebrería castreña lo tenemos en el brazalete de Lebuçâo (Armbruster y Perea, 1994: 76, lám. 3).

En el caso de nuestros torques se utilizó para el trazado de rosetas, corchetes, postas o trisqueles, en los discos exteriores de los terminales (Cangas de Onís E, Estela, Lebuçâo, Paradela do RioA, Provin-

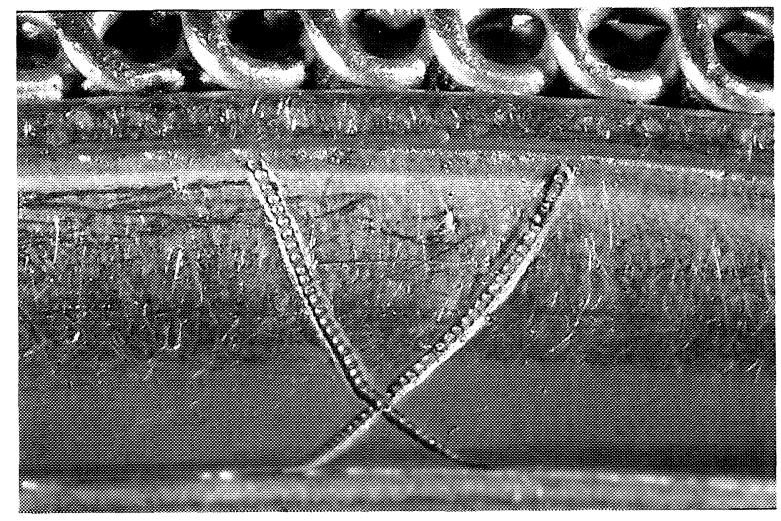

Lám. XV. Marca en forma de aspa, realizada con punzón complejo, sobre la zona central interior del aro del torques de Burela. cia de Lugo); como relleno de una zona en reserva se ha documentado en otros ejemplares no recogidos aquí, por ejemplo en dos torques de la región de Chaves (6) (Lám. IX). Pero este tipo de punzón no se utilizó únicamente como herramienta decorativa, sino que lo hemos documentado para trazar marcas sobre el aro, como el caso de la marca cruciforme del torques de Burela (Lám. XV). Finalmente, tenemos que señalar que se utilizó igualmente sobre objetos de bronce, fíbulas y placas de cinturón, de la Edad del Hierro procedentes de la Meseta norte (Romero Carnicero, 1991: 84-85).

\section{MORFOLOGÍA VERSUS TECNOLOGÍA}

La conclusión más evidente del análisis tecnológico expuesto en el apartado anterior es la gran variabilidad que existe en el proceso de fabricación de los torques con remates en doble escocia, tanto en las varillas, como en los terminales y ornamentaciones. Dicha variabilidad va más allá de una diferenciación cronológica o espacial, puesto que no existe una correspondencia entre morfología y técnica, es decir, el tipo no estaba asociado a un proceso de fabricación fijo. En nuestra opinión, esta circunstancia debe ser explicada a través del propio sistema de producción y, desde luego, justifica nuestros planteamientos previos de prescindir de las tipologías elaboradas hasta la fecha. En trabajos anteriores (Armbruster y Perea, 1994; Perea y Armbruster, 1998) ya habíamos comprobado la importancia del factor tecnológico como variable imprescindible a la hora de dar validez a los estudios basados en rasgos morfológicos que pueden enmascarar rasgos técnicos claves para su interpretación. Con ello entramos en las dos cuestiones fundamentales de este estudio; intentar acercarnos al sistema de producción que determinó estos comportamientos tecnológicos, por un lado; y por otro, la caracterización de un ámbito tecnológico castreño; en definitiva, plantear un sistema sociotécnico teórico (Perea, 1998, 1999 y e.p. a) que pueda explicar el fenómeno arqueológico que llamamos orfebrería castreña.

Dentro de las tres variables que se conjugan en todo ámbito tecnológico -técnicas, producción y cultura material-acabamos de definir esta última a través de la muestra escogida, los torques con remates en doble escocia. Nos faltan por definir las otras dos.

(6) Ver nota 5 . 


\section{Variabilidad tecnológica}

Distinguimos entre las técnicas que podemos calificar de locales o indígenas, que serían aquellas cuyo origen puede ser rastreado en el tiempo dentro de una amplia área geográfico cultural, en este caso la fachada atlántica; y las técnicas foráneas o asimiladas, procedentes de otro ámbito tecnológico ya definido.

La tecnología de la orfebrería castreña tiene su origen autóctono en la larga tradición del trabajo del oro durante la Edad del Bronce en la fachada atlántica peninsular, pero a su vez, integra tradiciones exógenas, procedentes sobre todo del ámbito tecnológico mediterráneo, en una amalgama muy específica. El ámbito castreño se caracteriza fundamentalmente por su mayor variabilidad al compararlo con los ámbitos anterior y posterior dentro de su área geográfica. En este sentido, entendemos por variabilidad la capacidad del orfebre castreño para escoger entre diversas soluciones técnicas ante problemas estructurales y ornamentales. Variabilidad tecnológica no significa variabilidad formal; existe una evidente homogeneidad en cuanto a la composición del objeto; por el contrario, observamos una sorprendente inhomogeneidad a la hora de llevar a la práctica formas y ornamentos que podríamos calificar de genéricos. Esta peculiaridad, que se da únicamente en los torques, parece tener su origen en problemas de demanda, de disponibilidad de materia prima y en los distintos conocimientos y experiencias del propio orfebre. Por cuestiones metodológicas analizaremos tecnológicamente este grupo de torques castreños separando los dos ámbitos identificados, el autóctono y el alóctono, como si fueran dos sectores distintos del artesanado, antes de llegar al producto final que, como acabamos de decir, supone un mestizaje con carácter propio.

Entre las técnicas identificadas como autóctonas podemos enumerar las siguientes: fundición del lingote preparatorio; vaciado a la cera perdida y vaciado adicional; trabajo de deformación plástica de placas, chapas y láminas gruesas, de barras macizas, varillas y alambres de diferentes secciones.

Entre las técnicas procedentes del ámbito mediterráneo que hemos visto aplicadas en la orfebrería castreña podemos enumerar: fabricación de hilos finos mediante técnica de torsionado que deja una huella helicoidal a lo largo del mismo; fabricación de esferas para granulado; soldadura como método de unión estructural, entre aro y terminales, y ornamental aplicada a la filigrana y el granulado.
Finalmente, es ineludible la cuestión europea, tantas veces aludida como esfera de influencia en la orfebrería castreña. No existen torques abiertos en época hallstática, compuestos por aro y dos remates independientes y unidos, si exceptuamos el torques de Vix, que se puede fechar hacia el 500 a.C., y en este caso, su técnica de fabricación se relaciona con el ámbito tecnológico atlántico de la Península Ibérica, aunque hay autores que no identifican ni esas conexiones, ni en esa dirección (Eluère et alii, 1989); además, el trabajo del oro, tanto en Hallstatt como en LaTêne, se caracteriza fundamentalmente por el trabajo sobre chapa o lámina con decoración repujada y estampada (Eluère, 1987). Tampoco se reconoce en la orfebrería castreña una relación directa y expresa con el ámbito céltico; por el contrario, hay elementos de la orfebrería centroeuropea que parecen haber sido influenciados por los orfebres de la Península Ibérica, tanto desde el ámbito Villena/Estremoz, del Bronce Final (Armbruster y Perea, 1994), como desde el propio ámbito castreño. Las relaciones entre la orfebrería hallstáttica y la orfebrería del I milenio a.C. en la Península no se pueden abordar en el marco de este estudio con la profundidad que merecen.

La segunda cuestión en cuanto a variabilidad tecnológica es la necesidad de diferenciar muy bien entre la variabilidad observada en los torques y la tecnología empleada en la fabricación de diademas/ cinturones y arracadas; este último grupo supone un sector diferente del artesanado que fabricaba los torques: probablemente lo practicaban distintos orfebres en distintos talleres. No se rastrean, en cinturones y arracadas, elementos morfotécnicos procedentes del ámbito atlántico del Bronce Final (Perea, 1995), ámbito que no producía adornos de oreja, ni cinturones/diadema, ni trabajaba sobre lámina muy fina repujada o estampillada, ni ornamentaba con filigrana y granulado, ni unía mediante soldadura.

\section{La producción}

Partimos de una consideración previa basada en los datos actuales sobre la metalurgia castreña del bronce (Ferreira da Silva, 1986: 165-192; Fernández-Posse y otros, 1993; Peña Santos, 1992). Se trata de una actividad generalizada, desde los niveles más antiguos de ocupación; de carácter doméstico, en el sentido de tecnología especializada; practicada a tiempo parcial, que no requiere infra-

T. P., 57, n. ${ }^{\circ} 1,2000$ 
estructura específica detectable arqueológicamente dentro del poblado (Naveiro, 1991: 78). Por el contrario, el carácter complejo de la tecnología del oro castreño, a pesar de no requerir una infraestructura especial para su práctica, sí condiciona fundamentalmente la transmisión de su conocimiento; por ello, y por cuestiones de evidente carácter económico que no es necesario desarrollar, pensamos que no es posible plantear un modelo de producción semejante al de la tecnología del bronce; lo que quiere decir que pensamos en el orfebre como una persona distinta al broncista.

El dato pertinente para establecer un modelo de producción para los torques castreños está en su variabilidad morfológica y técnica; un producto de estas características no encaja con un modelo de taller establecido y de carácter permanente. Conocemos sistemas de producción estables, por ejemplo en Cádiz durante el siglo IV a.C.; los productos que salen de este taller son variados, incluso existen distintas calidades dentro de un mismo tipo, pero son producciones de serie y en serie (Perea, e.p., b), con un diseño perfectamente normalizado y un sistema de fabricación en cadena en el que todo proceso técnico está predeterminado; la forma de intercambio mediante la que se distribuye la producción de este taller es de tipo comercial.

La producción castreña, por el contrario, se caracteriza por la improvisación de las soluciones ante problemas técnicos de diversa índole, lo que no quiere decir ausencia de conocimiento o impericia tecnológica; la variabilidad dentro de un rasgo morfológico - por ejemplo, el alambre enrolladoparece responder más a la disponibilidad de determinado material semielaborado, que a una intención diferenciadora de costes, calidades o esfuerzo artesanal. Los ejemplos son múltiples y la variabilidad se muestra tanto dentro de un misma pieza, como entre las distintas piezas entre sí.

La figura del orfebre ambulante ha sido defendida frecuentemente a lo largo de la historia de la investigación, y ciertamente parece encajar con el tipo de producción que hemos descrito. Defendemos la hipótesis del taller ambulante que da servicio a una amplia zona geográfica, que viaja con herramientas y conocimientos, pero que no posee la materia prima; ni por el entorno socioeconómico, ni por una cuestión de simple seguridad en los desplazamientos, parece razonable pensar que el orfebre poseía y transportaba el oro con el que trabajaba. La consecuencia de este sistema de producción es que el artesano debe buscar soluciones concretas en fun- ción del material de que dispone en cada momento y en cada lugar; este tipo de práctica artesanal no induce, desde luego, la normalización.

Sin embargo, podemos establecer un segundo modelo de producción posible, el encargo a distancia que se realiza a un taller estable, situado de forma fija o semipermanente -por ejemplo, estacional- en un punto de encuentro comercial, puerto o poblado costero, sobre todo en etapas cercanas ya a la romanización (Naveiro, 1991). Este segundo modelo no tendría porqué ser incompatible con el primero, sino diacrónico.

\section{COMPORTAMIENTOS Y PAUTAS}

Además de los factores que hemos venido considerando como variables para la definición de un ámbito tecnológico castreño, existen otros de índole diversa, relacionados con pautas y comportamientos recurrentes; son también reglas, con significado, que rigieron en su momento un proceso de comunicación ya concluido.

Empezaremos por una ausencia, la del contexto arqueológico de los hallazgos. Ya en otra ocasión (Perea y Sánchez-Palencia, 1995: 56) apuntamos que estos hallazgos eran mayoritariamente casuales. En el caso de las piezas que ahora nos ocupan, la misma circunstancia se repite, pero hay que añadir, igual que entonces, que un porcentaje alto se hizo en el entorno de un castro (Burela, Foxados, Recadieira I y II, Marzán, Provincia de Lugo, Viveiro y Vilas Boas); otro porcentaje se ha definido como depósitos por incluir material de desecho o semielaborado (Cangas de Onís (7), Estela, Foxados y Lebuçâo) (Pérez Outeiriño, 1992); finalmente, desconocemos los datos de otros muchos (Astorga, Lugo, La Madorra, Melide, Paradela, Ribadeo, San Lorenzo de Pastor II y Sin procedencia). Se puede concluir que existe un patrón estadísticamente significativo de abandono en el entorno de los lugares de habitación, sin relación con estructuras arqueológicas identificables, lo que encaja perfectamente con el concepto de depósito arqueológico: ocultamiento de uno o varios objetos valiosos o de especial significado, por motivos económicos, religiosos, funerarios, rituales o de otro tipo.

(7) Aunque parece que el conjunto de Cangas de Onís no fué un hallazgo conjunto y por tanto hay que poner en entredicho su carácter de depósito, las piezas estan intencionadamente fragmentadas de antiguo, por lo que el ejemplo es pertinente. Agradezco a Oscar García Vuelta esta información. 
Otra ausencia de especial significado es la de la moneda: en ninguno de los depósitos aparecen monedas; tenemos constancia de una excepción en el tesoro de Bedoya (Prieto, 1996: 199) que fecha el ocultamiento a partir del 91 d.C.

Nuestra propuesta es que todos los hallazgos que aquí recogemos deben ser considerados como verdaderos depósitos y no sólo los que presentan material de desecho o semielaborado; su distinto significado radicaría en la evolución diacrónica de los comportamientos sociales y económicos en los grupos castreños, según se trate de objetos aislados y en estado de uso, o de reaprovechamiento y asociados a otros materiales.

Pasamos ahora a una presencia bien visible pero ocasional, la de las marcas realizadas con estampillas o punzones, simples o complejos, que aparecen generalmente en la zona interior del aro. Dentro del material que aquí se recoge hemos identificado solamente una marca en forma de aspa en el torques de Burela, realizada con punzón complejo de media perla (Lám. XV); al margen de nuestro catálogo, hemos documentado otra, ya observada por Monteagudo (1952: 287), en un torques de extremos piriformes procedente de San Martiño do Porto (La Coruña) en forma de triángulo realizado con punzón complejo escaleriforme (Lám. XVI). En la bibliografía se recoge una marca repetida sobre un torques de extremos en doble escocia, hoy desaparecido, procedente del castro de Coaña (García y Bellido, 1942: fig. 14) y probablemente realizada con punzón complejo. Por su parte, López Cuevillas (1951: 43-44) considera como tal una incisión del torques de Sta. María de Rendar. Todos estos autores las interpretan como marcas de propiedad. Pero el mayor conjunto de torques marcados pro-

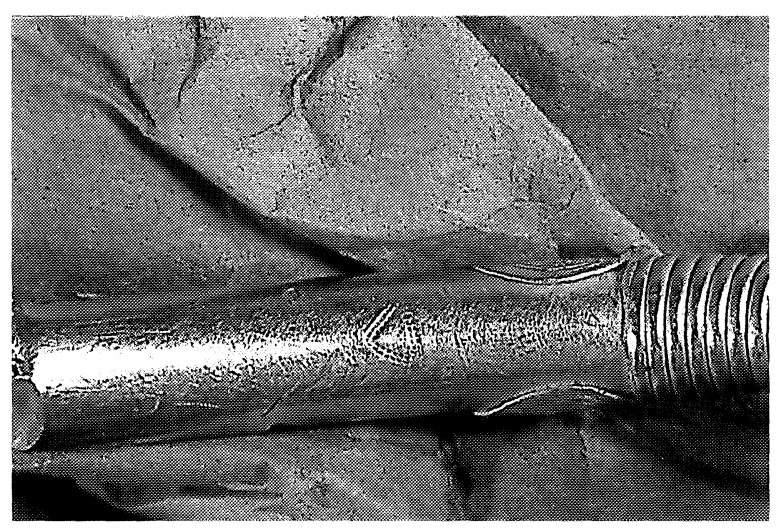

Lám. XVI. Marca triangular, realizada con punzón complejo, sobre la zona central interior del aro del torques de extremos piriformes de San Martiño do Porto. cede del tesoro de Arrabalde (Zamora), donde se han identificado hasta 7 signos diferentes, uno de ellos repetido en dos ejemplares, realizados con estampillas o punzones simples y combinados (Perea y Sánchez-Palencia, 1995: 55; Perea y Rovira, 1995: fig. 12), sobre torques en plata de varillas torsionadas. También sobre material de plata meseteño se han documentado cuatro marcas, dos de ellas en forma de $p i$ griega (Delibes y otros, 1993: 451-454).

Las interpretaciones más recientes oscilan entre marcas de propiedad (Delibes et alii, 1993: 453) y su carácter metrológico (Delibes et alii, 1993: 470; Galán y Ruíz-Gálvez, 1996: 162); esta última posibilidad no parece encajar bien con los torques castreños, considerando la variabilidad existente entre las composiciones de las aleaciones de oro (Hartmann, 1982) con las que están fabricados, lo que invalidaría una comparación de pesos al no tener en cuenta el material de fabricación del objeto (8). Creemos que lo realmente importante es el hecho de que sólo unos pocos ejemplares estén marcados y no la totalidad; esto individualiza unos torques con respecto a otros y les confiere un significado específico que tiene que estar, por tanto, en relación con una circunstancia que concurra en esos torques en particular y no en todos en general.

A este respecto también hay que tener en cuenta, por ser recurrente y constituir una pauta, que los punzones complejos, tanto para la estampación de marcas como para las distintas ornamentaciones, se emplearon solamente sobre torques con extremos en doble escocia y nunca sobre los de extremos piriformes.

\section{PROPUESTA}

El carácter polisémico de los torques queda demostrado por la propia evolución histórica de las formaciones sociales castreñas que no es lineal, homogénea ni igualitaria, desde la fase de formación hasta su plena integración en el mundo ideológico y económico romano. Pero en esta trayectoria, puesto que no vamos a hablar de significados permanentes o explicaciones definitivas, se puede observar una tendencia que es la que aquí vamos a intentar plantear.

(8) En este sentido tenemos que advertir que la interesante hipótesis de Ruíz-Gálvez (1995), que sigue Ladra Fernández (1997-98), según la cual los torques cstreños constituyen un sistema de pesos, está basada en una serie datos publicados que son erróneos (ver nota 3).

T. P., 57, n. $^{\circ} 1,2000$ 
La definición de lo que en aras de la simplificación llamamos sociedad castreña no está exenta de polémica que podría resumirse en dos visiones contrapuestas: la de una sociedad establecida en el territorio de manera permanente, con una economía agraria de tendencia a la intensificación y consecuente aparición y fortalecimiento de un poder basado en la posesión de la tierra y el control sobre los medios de producción (Peña Santos, 1992, 1996), y otra visión, la de una sociedad campesina, autárquica y sin un poder consolidado, al menos de forma visible y evidente (Fernández-Posse et alii, 1994,1998). Desde el punto de vista territorial, la discusión se centra en la afirmación o negación de un poblamiento jerarquizado (Criado, 1992). En efecto, lo que está en entredicho es la visibilidad de ese poder o de esa jerarquización, y en este sentido la existencia de una orfebrería compleja ha servido de argumento ocasional, cuando no fundamental, sobre todo al conectarlo semánticamente con la reorganización social, económica y territorial que sufre el mundo castreño al entrar en contacto con el romano. De este modo, aunque se admita que "el mundo castrexo hunde sus raíces más profundas en la Edad del Bronce, de la que surge como una evolución lógica e interna" (Peña Santos, 1996: 69), se niega toda posibilidad de acceso a esas raíces dado que "los rasgos tenidos por más peculiares y característicos del mundo castrexo proceden, en su práctica totalidad y mientras no se demuestre lo contrario, de los primeros tiempos del contacto entre los mundos indígena y romano" (Peña Santos, 1996: 85), incluida, por supuesto, la orfebrería.

Según todo lo expuesto, la semántica de los torques se basa en un referente y un oponente; la relación torques-castro y la oposición torques-arracadas. Creemos que los torques, en un momento de su larga trayectoria, constituyen una inversión comunitaria, un seguro colectivo ante situaciones de incertidumbre de una sociedad campesina en un mundo fragmentado; es fruto de un trabajo común y toma la forma de joya no porfuncionalidad social, sino porque llegó a adquirir el carácter de símbolo de poder económico y territorial; actuaría de seguro económico, pero también político, necesario para la subsistencia y reproducción del grupo. El torques carece de sentido individual, no pertenece a un jefe o a una élite, sino que se constituye en emblema ideológico de los diferentes grupos campesinos castreños. Efectivamente, el castro constituye una superestructura que actúa como cohesionador social, siempre visible en el paisaje (Fernández-Posse et alii, 1998:138-139) a través del recinto amurallado, otra inversión colectiva que cumple, a su vez, una función más social que defensiva, y que sirve de referencia para todas las actividades internas y externas de la vida castreña (Fernández-Posse $e t$ alii, 1998: 128). Este modelo encajaría en una fase del desarrollo de las sociedades castreñas en las que su fijación a la tierra es un hecho irreversible; por ello, defendemos un modelo de sociedad campesina en la que la coacción no es ejercida por un grupo dominante establecido, sino por la propia "trampa agrícola" de una producción diferida (Díaz-del-Río, 1995: 104-105; Fernández-Posse et alii, 1998: 146147). Es en este ambiente social e ideológico donde el fenómeno de las marcas que aparecen en algunos torques puede adquirir algún significado; en el ámbito de los contactos intergrupales, regalos, dones, pactos y pagos, deudas, favores y matrimonios, entre grupos autosuficientes pero en un permanente intercambio que posibilita la reproducción social. Desde esta particular perspectiva del contexto social castreño, nos parece banal la discusiónfuncional sobre el uso de los torques como adorno de cuello, masculino, femenino o neutro; es clarificador comparar los propios torques entre sí, desde todos los aspectos posibles.

Sin embargo, esta es una visión estática. El torques no perpetuó este modelo que acabamos de exponer, de hecho en época de integración romana, el torques adquirió significados de recompensa militar (Castro, 1992: 117 y ss.); hay que pensar que fue adoptando diferentes sentidos y usos a lo largo de una historia que creemos larga, desde un primer uso relacionado con el prestigio, heredero de la tradición del Bronce Final, hasta la pérdida de significados autóctonos y adquisición de otros nuevos en relación con el mundo ideológico romano, donde también situaríamos los depósitos con material troceado o de desecho dentro de un mundo irreversiblemente mercantilizado.

Si podemos definir el torques castreño como una manifestación colectiva de crisis es por su oposición a las arracadas, que son la manifestación individual del poder. Las arracadas son objetos muy ligeros, frente al peso de los torques, con carácter de adorno y, por tanto, de uso y propiedad individual y no colectiva; obtener la cantidad de oro aluvial necesaria para su fabricación requiere el esfuerzo de una persona durante unos diez días (Vázquez Varela, 1995: 160), mientras que el torques de Burela, de los más pesados, consumiría el trabajo de 12 personas durante dos meses al menos. Nunca se encuentran 
asociadas a los torques, excepto en el caso de tratarse de depósitos con material de desecho, como en los hallazgos de Estela y Masma (Pérez Outeiriño, 1982: 57 y 70) (9). Parece claro que las arracadas castreñas se movieron por circuitos sociales y económicos diferentes a los de los torques, y desde luego pertenecen, como ya hemos dicho, a un circuito artesanal igualmente distanciado.

Para terminar no queda más remedio que hacer alusión a la controversia cronológica; la misma dinámica interpretativa nos obliga a ello. Hasta aquí hemos ido argumentado que las raíces tecnológicas de este material arqueológico se pueden rastrear hasta el Bronce Final; igualmente el concepto morfológico de torques tiene su origen en esa etapa. Nos referimos a una línea, probablemente sinuosa pero no quebrada, desde el ámbito tecnológico Sagrajas/ Berzocana, incluidos los torques portugueses de Baiôes y otros, donde aparecen los extremos rematados en botón más o menos desarrollado, tanto en los torques (Inventario, 1993: 64-73) como en los brazaletes (Inventario, 1993: 106-121), e incluso remates cónicos voluminosos con una punta interior y ornamentación de círculos concéntricos (Inventario, 1993: 122-123); o los brazaletes de Cantonha (Inventario, 1993: 140-143) y Torre Vâ (Inventario, 1993: 144-147) con elementos ornamentales y estructurales comparables a los de los torques castreños. Por tanto, y ante la ausencia de contextos arqueológicos, tendremos que emplear estos criterios morfotécnicos para intentar situar los torques con remates en doble escocia en una posición más o menos cercana al Bronce Final o a la romanización.

Tecnológicamente el objeto mejor relacionado con el ámbito del Bronce Final, sobre todo con el ámbito Villena/Estremoz (Armbruster y Perea, 1994), es el brazalete de Lebuçâo, Valpaços, y por asociación, igualmente el torques de remates en doble escocia decorados con un motivo de roseta realizada con punzón complejo. El brazalete de Lebuçâo es una pieza clave para establecer la cronología más próxima a los inicios de la Edad del Hierro; su forma de cilindro cerrado vaciado a la cera perdida -en la fase previa al repujado de las molduras del cuerpo- con empleo de torno de eje horizontal y estrías paralelas en los bordes, lo relaciona estrechamente con los brazaletes tipo Villena/Estremoz (Armbruster y Perea, 1994: 76, lám.

(9) En las excavaciones efectuadas en Castro de Rei, Viladonga, en 1974, se encontró un torques dentro de una cabaña rectangular y una arracada en el exterior (Pérez Outeiriño, 1982: 82).
III). En este momento habría que situar la primera utilización de punzones complejos.

Pensamos que los rasgos del ámbito tecnológico castreño que definen un momento temprano de la Edad del Hierro serían los elementos estructurales macizos, la cera perdida y el empleo del torno para conformar el modelo de cera, y la fusión adicional para la unión de dos elementos estructurales. El torques característico de esta etapa sería Recadieira II, pero también habría que situar en momentos tempranos el ejemplar de Astorga. Otros, no incluidos en este trabajo, que tecnológicamente pertenecen esta etapa inicial serían los brazaletes de Cortez, Beja (Inventario, 1993: 122-123) y Torre Vâ, Beja (Inventario, 1993: 144-147).

La fijación de terminales macizos al aro mediante soldadura, en el hueco preparado al efecto, supone ya una nueva concepción tecnológica de la unión estructural que puede tener significado cronológico; por ello, situamos con posterioridad los torques fabricados mediante esta técnica, como los ejemplares de La Madorra.

Los remates huecos y la aplicación de hilos ornamentales para una filigrana que podríamos calificar de gruesa, supondría una complejidad tecnológica superior que se refleja en los ejemplares de Marzán y Burela, aunque este último, por su gran tamaño y peso, supone siempre una excepción. También la filigrana realizada con hilos finos, fabricados mediante torsión, y el granulado que vemos en Vilas Boas, con patrones decorativos recargados, tanto desde el punto de vista estético como tecnológico, no tiene lectura si no es en el marco de una orfebrería que no sólo ha asimilado conceptos técnicos mediterráneos, sino que los ha transformado en un lenguaje al servicio de su peculiar manera de expresión.

Este breve esquema cronológico que presentamos no pretende ser una receta evolucionista de fácil aplicación sino que supone únicamente la lectura provisional de un párrafo, dentro de un manuscrito de varias páginas que sería necesario completar para dar sentido a muchas de las palabras que probablemente hayamos traducido sin el matiz adecuado.

\section{BIBLIOGRAFÍA}

Armbruster, B. (1995): "Sur la technologie et typologie du collier de Sintra (Lisbonne). Un oeuvre d'orfèvrerie du Bronze Final Atlantique composé des types SagrajasBerzocana et Villena-Estremoz". Trabajos de Prehistoria, 52(1): 157-162.

T. P., 57, n. $^{\circ} 1,2000$ 
- (1996): "Zu den technologischen Aspekten der Goldfunde aus dem bronzezeitlichen Schatzfund von Caldas de Reyes (Prov. Pontevedra)". Madrider Mitteilungen, 37: 60-73.

- (1998): "Quelques aspects technologiques de l'orfèvrerie du Bronze Final au début de l'Age du Fer, au Portugal et Galice". En G. Nicolini y N. Dieudonné-Glad (eds.): Les métaux antiques: travail et conservation. Actes du Colloque Int. de Poitiers 1995. Monographies Instrumentum, 5. Montagnac: 53-58.

- (1999): "Techniques d'orfèvrerie préhistorique des tôles d'or en Europe atlantique des origines à l'introduction du fer". En C. Cauuet (ed.): L'or dans l'Antiquité. De la mine a l'objet. Supplément Aquitania, 9: 237-249.

- (e.p.): Goldschmiedekunst und Bronzetechnik. Studien zum Metallhandwerk der Atlantischen Bronzezeit auf der Iberischen Halbinsel. Monographies Instrumentum. Montagnac.

Armbruster, B. y Perea, A. (1994): "Tecnología de herramientas rotativas durante el Bronce Final atlántico. El depósito de Villena". Trabajos de Prehistoria, 51(2): 69-87.

Balseiro García, A. (1994): El oro prerromano en la provincia de Lugo. Diputación Provincial, Lugo.

- (1997): “Aproximación a la orfebrería castreña: el tesoro de Bedoya". En V. Alonso Troncoso (ed.): Ferroterra Galaico-Romana. Ferrol: 49-67.

BouZA BREY, F. (1965): "Tres torques áureos de Galicia". Cuadernos de Estudios Gallegos, XX(60): 5-11.

CARDOZO, M. (1942): "Una pieza notable de la orfebrería primitiva". Archivo Español de Arqueología, 15: 93-103.

CASTro Pérez, L. (1990): Os torques prehistóricos. Biblioteca de Divulgación, Universidade de Santiago de Compostela.

- (1992): Los torques de los dioses y de los hombres. Vía Láctea, A Coruña.

Criado Boado, F. (dir.) (1992): Arqueología del Paisaje. El área Bocelo-Furelos entre los tiempos paleolíticos y medievales. Arqueoloxía/Investigación, 6. Santiago de Compostela.

Delibes, G.; Esparza, A.; Martín, R. y Sanz, C. (1993): "Tesoros celtibéricos de Padilla de Duero". En F. Romero, C. Sanz y Z. Escudero (eds.): Arqueología Vaccea. Estudios sobre el mundo prerromano en la cuenca media del Duero. Junta de Castilla y León. Valladolid: $397-470$.

Díaz-Del Río Español, P. (1995): “Campesinado y gestión pluriactiva del ecosistema: un marco teórico para el análisis del III y II milenios a.C. en la meseta peninsular". Trabajos de Prehistoria, 52(2): 99-109.

DRESCHER, H. (1958): Der Überfangguss. Ein Beitrag zur Geschichte der Metalltechnik. Mainz.

Eco, U. (1995): Tratado de Semiótica General. Editorial Lumen, Barcelona.

Eluère, C. (1987): "Celtic Gold Torcs". Gold Bulletin, 20: 22-37.
EluÈre, C. y otros (1989): "L'or et l'argent de la tombe de Vix". Bulletin de la Société Préhistorique Française, 86(1): 10-32.

Fernández-Posse, M.D. y SÁNChez-Palencia, F.J. (1998): "Las comunidades campesinas en la cultura castreña". Trabajos de Prehistoria, 55(2): 127-150.

Fernández-Posse, M.D.; Montero, I.; SÁnChez-Palencia, F.J. y Rovira, S. (1993): "Espacio y metalurgia en la Cultura Castreña: la zona arqueológica de Las Médulas". Trabajos de Prehistoria, 50: 197-220.

Fernández-Posse, M.D.; SÁnChez-Palencia, F.J.; Fernández Manzano, J. y Orejas, A.: "Estructura social y territorio en la Cultura Castreña". Primer Congreso de Arqueología Peninsular (Porto, 1993). Actas IV. Trabalhos de Antropologia e Etnologia, 34(3-4): 192212.

Ferreira da Silva, A.C. (1986): A Cultura Castreja no Noroeste de Portugal. Paços de Ferreira.

ForMigli, E. (1993): "Sulla tecnica di construzione dei fili d'oro nell'oreficeria etrusca". En Outils et ateliers d'orfèvre des temps anciens, Int. Symposium, Saint Germain-én-Laye 1991.Antiquités Nationales, mémoir 2: $35-38$

Galán, E. y Ruiz-Gálvez, M. (1996): “Divisa, Dinero y Moneda.Aproximación al estudio de los patrones metrológicos prehistóricos peninsulares". En M.A. Querol y T. Chapa (eds.): Homenaje al Profesor Manuel Fernández-Miranda, Complutum, extra II: 151-166.

García y Bellido, A. (1942): "El castro de Coaña (Asturias)".Archivo Español de Arqueología, XV(48): 216 244.

Hartman, A. (1982): Prähistorische Goldfunde aus Europa II. Studien zu den Anfängen der Metallurgie, Band 5. Berlin.

HunT, L.B. (1980): "The long history of lost wax casting. Over five thousands years of art and craftmanship". Gold Bulletin, 12(2): 63-79.

Inventario do Museu Nacional de Arqueología (1993): Colecçâo de ourivesaria I. Do Calcolítico à Idade do Bronze. (Coord. B. Armbruster y R. Parreira). Instituo Português de Museus. Inventario do Património cultural Móvel. Lisboa.

LADRA FERNÁNDEZ, X.L. (1997-98): “Ouros no desterro: notas encol de dous conxuntos inéditos de ourivesaría castexa actualmente depositados no M.A.N.". Boletín do Museo Provincial de Lugo, VIII(1): 45-78.

LENERZ DE WILDE, M. (1992): Iberia Celtica. Archäologische Zeugnisse keltischer Kultur auf der Pyrenäenhalbinsel. Stuttgart.

López Cuevillas, F. (1932): Os torques do Noroeste hispánico. Arquivos do Seminario de Estudos Galegos, IV: 97-130.

- (1951): Las joyas castreñas. Madrid.

Monteagudo, L. (1952): "Torques castreños de alambres enrollados". Archivo Español de Arqueología, XXV: 287-296.

T. P., 57, n. $^{\circ} 1,2000$ 
NAVEIRo LóPEZ, J.L. (1991): El comercio antiguo en el NW peninsular. Monografías urxentes do museu, A Coruña.

NicOlARDot, J.P. y GAUCHER, G. (1975): Typologie des objets de l'Age du Bronze en France 5: Outils. Societé Préhistorique Française, Commission du Paris.

NiCOLINI, G. (1990): Techniques des ors antiques. La bijouterie ibérique du VIIe au IVe siècle. Picard. Paris.

Peña Santos, A. (1992): Castro de Torroso (Mos, Pontevedra). Síntesis de las memorias de las campañas de excavaciones 1984-1990. Arqueoloxía/Memorias, 11, A Coruña.

Perea, A. (1990): "Estudio microscópico y microanalítico de las soldaduras y otros procesos técnicos en la orfebrería prehistórica del sur de la Península Ibérica". Trabajos de Prehistoria, 47: 103-160.

- (1995): "La metalurgia del oro en la fachada atlántica Peninsular durante el Bronce Final: interacciones tecnológicas”. En M. Ruíz-Gálvez (ed.): "Ritos de Paso y Puntos de Paso. La Ría de Huelva en el mundo del Bronce Final europeo". Complutum, extra 5: 69-78.

- (1998): "Arqueometal-úrgia de l'or. El Projecte Au". Cotazero, 13: 43-49.

- (1999): “'Proyect Au' for the study of goldwork technology and the concept of 'Technological Domain Systems"”. En S.M.M. Young, A.M. Pollard, P.Budd y R.A. Ixer (eds.): Metals inAntiquity. BAR International Series, 792. Oxford: 68-71.

- (e.p. a): "Tecnología, política y sociedad: el ProyectoAu". Saguntum.

- (e.p. b): “Comportamientos de mercado en la producción orfebre del taller de Cádiz". En Intercambio y comercio preclásico en el Mediterráneo, I Coloquio del Centro de Estudios Fenicios y Púnicos, Madrid, Noviembre 1998 .

Perea, A. y Armbruster, B. (1998): “Cambio tecnológico y contacto entre Atlántico y Mediterráneo: el depósito de El Carambolo, Sevilla". Trabajos de Prehistoria, 55(1): 121-138.

Perea, A. y Rovira, S. (1995): “The gold from Arrabalde". En G. Morteani, y J.P. Northover, (eds.): Prehistoric Gold in Europe. Mines, Metallurgy and Manufacture. NATO ASI series, Kluwer. Dordrecht: 471-490.

Perea, A. y SÁnchez-Palencia, J. (1995): Arqueología del Oro Astur. Orfebrería y Minería. Caja de Asturias.
PÉREZ Outeiriño, B. (1982): De ourivesaria castrexa. I Arracadas. Boletín Auriense, anexo 1, Ourense.

- (1990): "Achega tipoloxica para o estudio dos torques aureos do NW". Gallaecia, 12: 139-151.

- (1992): "Almacenamento da materia prima entre os ourives castrexos: lingotes planoconvexos". En F. Acuña (coord.): Finis Terrae. Estudos en lembranza do Prof. Dr. Alberto Balil. Santiago de Compostela: 97123.

PINGEL, V. (1992): Die vorgeschichtlichen Goldfunde der Iberischen Halbinsel. Eine archäologische Untersuchung zurAuswertung der Spektralanalysen. Madrider Forschungen 17, Berlín.

Prieto Molina, S. (1996): "Los torques castreños del Noroeste de la Península Ibérica”. Complutum, 7: 195223.

RADDATZ, K. (1969): Die Schatzfunde der Iberischen Halbinsel vom Ende des dritten bis zur Mitte des ersten Jahrhunderts vor Chr. Geb. Untersuchungen zur hispanischen Toreutik. Madrider Forschungen 5, Berlín.

RoMero CARNicero, F (1991): "El artesanado y sus creaciones". En "Los Celtas en la Península Ibérica". Monográfico de Revista de Arqueología: 82-91.

RuIZ-GálveZ, M. (1995): "From Gift to Commodity. The changing meaning of precious metal in later Prehistory of the Iberian Peninsula". En G. Morteani y J.P. Northover (eds.): Prehistoric Gold in Europe. Mines, Metallurgy and Manufacture. NATO ASI series, Kluwer. Dordrecht:45-63.

SCHÜLE, W. (1960): "Probleme der Eisenzeit auf der Iberischen Halbinsel". Jahrbuch Römisch Germanisches Zentral Museum, 7: 59-125.

Thevenot, J.P. (1998): “Un outillage de bronzier: Le dépot de La Petite Laugère à Génelard (Saône-et-Loire)". En C. Mordant, M. Pernot y V. Rychner (eds.): L'Atelier du Bronzier en Europe du XXe au VIIIe siècle avant notre Ėre. Actes du Colloque International, Bronze 96, Neuchâtel-Dijon, II: 123-144.

VÁzquez VARElA, J.M. (1995): "Etnoarqueología de la extracción del oro de los ríos en el noroeste de la Península Ibérica". Trabajos de Prehistoria, 52(2): 157-161.

VILlAAMIL y CASTRO, J. (1874): "Adornos de oro encontrados en Galicia”. Museo Español de Antigüedades, III: 545-555.

T. P., 57, n. $^{\circ} 1,2000$ 